\title{
MICROSAVINGS AND MARKET SATURATION: THE EVOLUTION OF DIVERSITY IN SAVING PRODUCTS
}

\author{
Philipp E. Otto* and ArVIND Ashta**
}

\begin{abstract}
Saving behavior influences economic development in many possible ways. The paradox of thrift stresses the negative effects of increased individual savings. How does this relationship transfer to microfinance and to microsavings in particular? Based on savings data of differently developed countries, we investigate the relationship described by the triangle of the availability of saving products, savings behavior, and development. The data supports the assumption of the proposed saturation triangle that with an increased number of MFIs active in a country, the average deposit per MFI decreases. Furthermore, the savings product saturation of a country is linked to economic as well as social developments.
\end{abstract}

Keywords: saving deposits, microfinance institutions, developmental research, technological change.

JEL: O22, O47, R11.

\begin{abstract}
"The man who saves, be he prince or peasant, is the benefactor of his country; for it is capital which bestows all necessaries and all comforts, which rescues population from poverty, which sustains and increases their numbers. Nothing can be more fatal to the happiness of a people than to bring profit into discredit".
\end{abstract}

(Bonamy Price, 2010, page 128)

\section{INTRODUCTION}

Much has been said about the advantages and disadvantages of savings. One key concept in this field, which became famous under Keynes (1936), is

* European University Viadrina, corresponding author E-mail: otto@europa-uni.de.

** Banque Populaire Chair in Microfinance at the Burgundy School of Business. 
the paradox of thrift ${ }^{1}$. It postulates that if everyone saves an increasingly larger proportion of income, people altogether would become poorer. This controversial relationship is explained by increased savings representing a diminishing circular flow of income, leading to an overall slowdown of the economy. In general, the paradox of thrift highlights that total savings might fall when individual savings tries to rise, thus harming the economy. Saving (or thrift) increasingly becomes a social vice during economic slowdowns in industrial countries. In developing countries, the need for investment is even more evident, but does this require increased savings to be fulfilled first? Saving behavior can be crucial for building up wealth and possibly for creating freedom of action for prolonged investment.

Considerable research has been done in the field of microfinance since the Rural Finance Program of the Ohio State University (i.e., Adams, 1978, 1988), with Jonathan Morduch (1999) demanding systematic experimental investigations, although with little consideration of the saving controversy within microfinance. The sheer growth of the microfinance sector ${ }^{2}$ leads to project diversity and various implementation formats. On the one hand, the characteristics of microcredit products differ fundamentally. On the other hand, implementation conditions are rather diverse. Both these factors strongly influence a product success. Many studies illustrate the variety of growth patterns and corresponding demand in developing countries. The degree of poverty as well as other determinants for being disadvantaged have been discussed as necessary conditions for micro-lending to lead to fundamental economic improvements. For example, targeting the vulnerable (Amin, Rai, and Topa, 2003) or the core poor (Weiss and Montgomery, 2005) has been stressed $^{3}$. More generally, the effectiveness of an intervention in regard to

1 The overall relation illustrating this paradox of thrift is described by Keynes (1936, p. 84) as: "For although the amount of his own saving is unlikely to have any significant influence on his own income, the reactions of the amount of his consumption on the incomes of others makes it impossible for all individuals simultaneously to save any given sums. Every such attempt to save more by reducing consumption will so a ect incomes that the attempt necessarily defeats itself." The formulation of the paradox itself can be traced back to John M. Robertson in 1892 (for a historical overview see Nash and Gram, 1969).

2 The platform Microfinance Information eXchange (MIX) reports a strong increase in assets for microfinance institutions between the year 2000 (\$2 billion) and 2010 ( $\$ 70$ billion), with the number of microfinance institutions reporting their data also increasing steadily from 200 in 2000 to 1100 in 2010. The peak in microfinance providers appears to have been reached in the year 2008 with nearly 1300 institutions reporting on MIX. But as reporting on MIX is voluntary, a larger proportion of the smaller microfinance institutions is not captured under this device.

3 There is a growing criticism that microfinance is becoming increasingly directed to consumer lending and leading to over-indebtedness (i.e., Bateman, 2010). The success story of mi- 
poverty alleviation depends on the current developmental situation of a country. At the extreme, and in analogy with the paradox of thrift, with each additional initiative the marginal impact is reduced. Definitely, the stage of development of a country has to be addressed when determining the expected impact of an intervention. While impact is central for evaluating project differences, in this study we simply focus on the diversity of existing products, notably savings, as a measure of development.

According to Collins et al. (2010), the poor suffer from a triple whammy: first, their incomes are low; second, these incomes are not only irregular but also uncertain; and, third, they do not have the necessary institutions to provide support with these problems. Their results, based on financial diaries, indicate that the poor need savings products to be able to get over di cult periods. Numerous further studies stress the importance of facilitating savings (for reviews see i.e., Matin, Hulme, and Rutherford, 2002; Vogel and Burkett, 1986). As we will see from our analysis, once the possibility for deposits is provided, this facility is heavily used. From this it can be inferred that for the poorest of the poor saving appears to be more important than credit to cope with future risk. Borrowing on its own can impose high levels of stress, and microcredit is even blamed for increasing suicides rates (Ashta, Khan, and Otto, 2011), but savings could help to lower this kind of stress. Therefore, the savings route can be proposed as a promising alternative to loans. Gadway and O'Donnell (1996), for example, propose a "savings-first strategy" which emphasizes the greater need for liquidity over credit. In many regions microfinance institutions (MFIs) are not allowed to take deposits. However, when they do, there are more depositors than borrowers. From this it can be concluded that poor people need avenues for savings too. However, it is possible that more depositors with concomitant higher deposits could be attracted if there were more attractive savings products. This is a little researched area: what lessons can the experience of the mature financial services sector in developed countries offer developing countries? Because it is assumed that informal savings forms the major source of funds for microenterprises (i.e.,

crofinance was that it would help the poor to start small businesses (in large numbers) and thereby initiate economic development which is sustainable. However, it is well recognized that only the active poor should be microfinance clients. The very poor or the ultra-poor are expected to be part of safety net programs since they are neither able to save nor to borrow (Sachs, 2005; Tavanti, 2013). However, there is supporting evidence that subsidized lending to the ultrapoor might bring them up to the level where they can take conventional loans (Armend ariz and Morduch, 2010). The main question here is the definition of "ultra-poor." The Microcredit Summit Campaign in 2011 indicates that out of the 195 million micro-borrowers 124 million were the "poorest of the poor" - living on less than $\$ 1.25$ a day. 
Gugerty, 2007), reliable savings accounts should be the entry point for providing financial services to the active poor. Furthermore, many more people can be reached by offering savings products than through loan offers - irrespective of individual wealth level or other social instruments. Thus, the central focus of our study is whether the level of saturation with the existing saving products is a necessary condition for alleviating poverty. Are saving products lacking in certain regions? Do we need to diversify saving offers? Will product diversity add to or subtract from the well-being of the poor?

First, existing literature on saving behavior and success factors are discussed, distinguishing between developing and developed countries. Second, the research aim and approach are specified. In the third section, the data of regional saving product differences are described and analyzed. The fourth section discusses the results and provides an outlook for future developments.

\section{BACKGROUND LITERATURE}

The literature provides many different approaches defining growth or measuring development which can be investigated as "success indicators". These cover the impact an institution might have as well as its outreach and sustainability. More general measures of "well-being" are further increasing the pool of possible evaluation standards. In relation to specific product characteristics, the different measures provide mixed and often contradicting evidence. Thus, the evaluation criterion appears crucial for determining success in different markets, as savings might only relate to specific measures of progress. In any case, the demand for su cient financial services in developing countries illustrates its potential for improving overall well-being.

Naturally various di culties exist in regard with the concept of development and well-being. First, the definition of development is manifold and potentially includes economic as well as non-economic factors. Second, the measurement of impact remains complex. Third, the developmental outlook may differ. Here, Hulme (2000) stresses the importance of internal success monitoring, implying that the definition of success is perspective dependent and the increase of overall well-being is di cult to achieve and measure. Therefore, we must always ask ourselves where and for whom improvements have been achieved.

\subsection{Microfinance success factors}

Microcredit has been a success in terms of outreach in many countries such as Bangladesh, Bolivia, Bosnia-Herzegovina, India, Pakistan, Philip- 
pines, etc. (Patten, Rosengard, and Johnston, 2001; Yunus, 2003). However, in many of these countries microcredit has also had its share of crises (Rhyne, 2001; Vogelgesang, 2003; Marconi and Mosley, 2006; Chen et al., 2010; Constantinou and Ashta, 2011). In this sub-section, we discuss the following question: what makes microfinance outreach successful in some countries but not in others and is it possible to separate impact from culture?

Allaire et al. (2009) focus on what distinguishes Morocco from its North African neighbors (Algeria, Tunisia, Libya, and Egypt) where the culture is similar but institutions differ. A case study approach establishes a number of factors which may determine the success of microfinance in a country, including the fact that there are specific laws on microfinance, but different ones, in Morocco and Tunisia. In their results, the success of microfinance is mainly linked to population density, geographic size of a country, and its poverty, as well as the amount of international donor funds it has received. The more densely populated, the smaller, and the poorer a country is, the more successful MFIs are. The availability of oil exports as a source for revenues led to a delay in developing microfinance, but establishing a specific legal framework for microfinance, as was done in Morocco, helps to foster its growth. Also the existence of Apex organizations, for centralizing international aid and redistributing funds, could lead to lower donor participation since their directional choices are reduced and an extra level of bureaucratic costs is imposed ${ }^{4}$. Ashta and Fall (2009) extend this study to another African region, namely West Africa. To control for the legal factor, they investigate a part of West Africa where eight countries (Benin, Burkina Faso, Côte d'Ivoire, Guinea-Bissau, Mali, Niger, Senegal, and Togo) are bound by a common monetary and economic union and its regulations promulgated by the Central Bank of West African States (BCEAO). No regulatory differences ${ }^{5}$ can explain observed country variations here and other factors should become more apparent. For evaluating microfinance growth, twenty-three quick query indicators reported by the World Bank are investigated for these countries (like GDP, fertility rate, life expectancy, etc.). In addition, six World Bank public governance indicators (voice and accountability, political stability, government effectiveness, regulatory quality, rule of law, and control of corruption) are compared. Here, the success of microfinance is linked to eco-

4 The study by Allaire et al. (2009) uses microcredit in Northern African countries as the sole basis for analyzing microfinance institutions, legal frameworks, and impact. Please note that this study was based on microcredit figures till 2007. Since then, microcredit in Morocco has experienced a decline. According to MIX, larger Moroccan institutions also do not o er microsavings.

5 Other regions of Africa may have di erent laws depending on the kind of MFI. 
nomic performance (in terms of both levels of per capita income and growth) as well as regulatory and public governance (with the amount of private remittances being received in a country and with life expectancy at birth). Again, the study is based on microcredit and not microsavings. The latter is the focus of this paper, claiming a dependency between savings rates and development.

Direct measures like GDP, unemployment rate, or illiteracy are useful for describing developmental success. Many different indicators have been proposed for evaluating the success factor "growth" 6 , which are differently defining successful economic development. In this paper, some performance indicators reflecting economic and social development will be investigated in more detail, relating them to the sophistication of the existing saving possibilities offered by financial service institutions of a country. Before this relationship is elaborated on in more detail, it is important to stress differences and similarities in saving behavior of developed versus developing countries.

\subsection{Savings in developed countries}

The neglect of savings as a collateral for increasing loans might be of more general nature than just a problem pertaining to the microfinance sector. Consumer research of saving behavior becomes increasingly aware of behavioral shortcomings which keep people from providing means for the future. This problem can be interpreted differently. Shortcomings can be seen as akrasia, explained by bounded rationality or thraough, for example, hyperbolic discounting (Laibson, 1996). Alternatively, temporal inconsistencies can be described as an internal conflict which needs to be solved (Freud, 1914/1956; Schelling, 1980). Increasingly the problem of saving is investigated as a self-control issue (Ainslie, 1975; Schelling, 1984; Thaler and Shefrin, 1981). The latter allows for ways of improving saving rates by the means of self-control mechanisms and diverse possibilities for improving self-control have been described in the literature. Simple examples include mental accounting, default settings, or information structuring (i.e., Sunstein and Thaler, 2003; Thaler, 1985; Thaler, Sunstein, and Balz, 2010).

A typology of different mechanisms for coping with the "savings gap" is provided by Otto, Davies, and Chater (2007) describing different ways for

6 Popular indicators are the Index of Sustainable Economic Welfare (ISEW), the Genuine Progress Indicator (GPI), the Fordham Index of Social Health (FISH), the UN's Human Development Index (HDI), and the Index of Economic Well-Being (IEWB) - just to name a few. 
achieving self-control by manipulating the choice situation. These mechanisms are differently utilized and three general areas can be distinguished for achieving better self-control: (i) restricting the decision space, (ii) manipulating the environment, and (iii) manipulating contingencies. These different types of mechanisms can be used separately or in combination and are seen as prominent tools for improving self-control. Restricting the decision space (i) is the most common and can be achieved through automatic saving transfers, spending budgeting, or full elimination of unwanted alternatives (i.e., through lock away periods). Manipulating the environment (ii) can be done either by supporting cues for desired behavior or by eliminating cues for opposing actions (i.e., through enhanced or limited information processing). These can be specific reminders for a commitment as well as the avoidance of those circumstances which are often leading to an unwanted behavior. The direct manipulation of contingencies (iii) is the standard utility based approach for integrating desired action over time (i.e., through penalties or bonuses). Applying the different approaches together, we can examine the claim that the available financial products on the market do not reflect the consumers demand for self-control and thus, the financial services sector is not su ciently developed for serving demand diversity. Limited availability of such mechanisms can be even stronger in countries with less developed financial services. Thus, the general lack of tailored products is more prevalent, although informal financial arrangements with corresponding social control mechanisms might compensate for these shortcomings to some degree.

\subsection{Savings in developing countries}

Microsavings have been playing an important role from the beginning of financial services programs in less developed countries. Several initiatives started with the assumption that the main failure of developing countries is their inability to save (compare Otero, 1989) or, more generally, a prevalent lack of self-control. Bauer, Chytilov'a, and Morduch (2012) support this assumption of differences in self-control with present bias. In analogy with Laibson (1992), they show for a rural sample in Karnataka (India) that experimentally measured hyperbolic discounting is significantly related to the debit-credit-dimension, with stronger hyperbolic discounting of women who are saving less and borrowing more.

Saving behavior seems to remain an important issue and many projects stress this component of saving mobilization in MFIs (for an overview of different initiatives focusing this issue in microfinance see Fiebig, Hannig, and 
Wisniwski, 1999). Financial institutions show a growing awareness concerning the savings side and their combining potential with loans. Certainly, the poor in developing countries are not sitting idle and are forming informal savings arrangements (i.e., tontines, RoSCAs, mutual funds, or kitty parties). Such funds may serve savings, credit, and insurance functions. Motivations include risks associated with hoarding, eliminating the need to maintain large sums in one place, little paperwork, no authorizations, keeping money away from relatives and submitting to social pressure to save, as well as possibilities to receive the sum earlier in case of an emergency (Swaan and Linden, 2005). However, such informal funds existed even in the 19th century in Europe, but by and large they disappeared with the spread of government and commercial financial institutions (Swaan, 2005). Informal arrangement could be important and show specific features which have been partly used in MFI products, although they are di cult to evaluate quantitatively. Different self-regulation mechanisms evolved in the field and directly reflect individual demands. Here forced and voluntary saving mechanisms as well as products with or without social intermediation can be distinguished. Selfregulations like rotation schemes, cooperatives, or deposit collectors illustrate the demand for saving schemes, but also show current limitations concerning security and vulnerability to defaults. Informal arrangements often have sophisticated selection and monitoring systems as well as being highly flexible in nature. Nonetheless, the often negative interest rates of these "products" further stresses the strong demand for security including selfcontrol through, for example, regular payments or peer pressure ${ }^{7}$. It seems that formal financial institutions can reduce some of the weaknesses of informal solutions and potentially offer more products to meet unsatisfied personal demands. Informal arrangements are based on trust and community values, but economic development could also change these. Increased mobility creates neighborhoods with different communities and reduces trust between neighbors. At the same time, departing migrating workers, even if they continue in their RoSCAs for a while, will eventually leave. Thus, even if banks are not present to serve these communities directly, they need more formal savings and mutual financial institutions (such as chit funds present in India, Smets, 2005). In this regard, a continuum of self-control demands from developed to developing countries can be assumed, but strong behavioral differences are expected on the individual level.

7 A study by Dupas and Robinson (2008) directly shows, for a sample of entrepreneurs in Kenya, that such saving constraints exist. The simple provision of interest-free saving accounts (with withdrawal fees) helped, there, to increase investment levels in the case of some entrepreneurs. 
Overall financial sophistication should foster economic growth and corresponding social developments in a country, although developments in the different areas could simply support each other. A mutual dependency can also be assumed for the savings levels observed in a country and a country's economic as well as social development. This paper provides a conceptual framework for investigating the relationship between product availability, saving behavior, and overall development. Only first dependencies are investigated here to support these relations. More complex statistical methods would need a better database, but would not necessarily lead to better interpretations of causality. However, these directional relations might be drawn with more sophisticated data over longer time horizons.

\section{RESEARCH QUESTION AND METHODOLOGY}

Equally for developed countries (Otto et al., 2007) as well as for developing countries (Bauer et al., 2012), self-control enabling products can be demanded. When self-control needs are met by an availability of self-control devices, increased market saturation with saving products could directly lead to higher saving rates. In this regard, a relationship between saving behavior and economic development can be postulated. Thus, our research question is twofold:

(i) Do savings increase with the number of self-control devices available on the market?

Irrespective of the developmental status, a country's saving rate can be increased by the provision of saving possibilities. The better these saving products reflect the demand for self-control, the higher personal savings are. Although in developed countries an increase might be achieved, scope for improvement is mainly in developing countries with a less saturated savings market. In developed countries the savings rate is assumed to be rather stable, as the number or suitability of savings products does not change fundamentally. In developing countries the savings rate is expected to increase (at a decreasing rate) with the number of savings products available in the local market.

(ii) Do increased savings link to enhanced economic and social development?

Contrary to standard economic assumption that spending is the basis for economic growth as postulated by the thrift paradox, saving behavior enabling development is postulated for the poorest of countries, in line with the microfinance literature. Again as under (i) above, the potential for improvement is assumed to weaken with the development level. Thus, the 
higher the saving rates are at a given point in time, the lower the incremental effect of additional savings on future development is. Social factors are expected to improve in line with the economic development, based on increased savings and self-control.

For both questions it is necessary that the number of offered self-control devices, in form of savings products, influences saving behavior. The behavioral weakness in self-discipline is assumed to decrease with the number of existing saving mechanisms provided by financial services. In developing countries the saving potential is weakened by the current situation of fully absent or only partly provided mechanisms, for example through informal markets. The overall conceptual relations are as depicted in Figure 1. This describes a "saturation triangle" between availability of savings products in the market (ASP), the amount of assets saved (Savings), and a country's economic as well as social development.

Figure 1: Saturation triangle between availability of savings products (ASP), savings levels, and a country's development

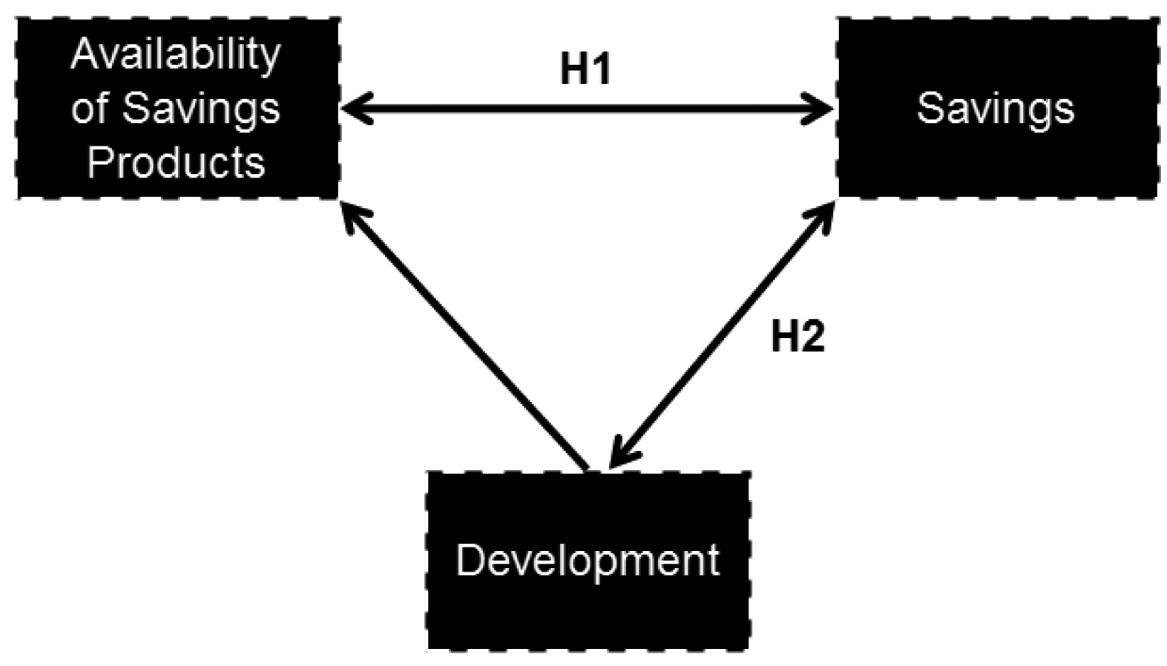

The first bidirectional arrow (H1) indicates that ASP leads to higher savings as does increased deposits lead to more savings products available on the market. Savings and development are also bidirectionally connected $(\mathrm{H} 2)$, with more savings leading to more development and vice versa. Development also directly influences ASP. These different hypotheses form the triangle of market saturation based on self-control mechanisms. On the one 
hand, the availability of savings products increases savings by overcoming human imperfections and fulfilling the need for diverse control mechanisms. Savings then might feedback, as an increase in savings could itself attract more providers of savings products as it would lead to lower overheads per unit or because more competition enters the market. On the other hand, savings lead to development facilitating investments. Development again may lead to more savings because people no longer need to consume all they have. However, richer people may also look for social spending aimed at improving the lot of their less fortunate brethren. Closing the triangle, development may itself lead to availability of more savings products as technology and infrastructure get affordable. Thus, the number of savings products has a two way link with savings which have a two way link with development and which in turn has a one way link back to the amount of savings products. These relationships together describe the assumed dependencies regarding savings market saturation and form the conceptual model of a saturation triangle.

In this paper, however, we do not investigate all relationships of the postulated saturation triangle and only concentrate on the connection between ASP with savings and savings with development (without investigating the direction of these relations). The dependence of saving behavior on the provided self-control mechanism is inherent in the savings amounts, but only reflects this relationship. The provision of financial services is simply approximated by the number of MFIs active in the regional market, also reflecting the strength of interventions ${ }^{8}$. As a consequence, in this paper the main relationship between savings behavior and development is tested. This appears to be the most critical connection, but only both relationships together would ultimately contradict the assumption of thrift - here adapted for development measures. These preliminary tests, being part of the saving saturation assumption, are condensed in the following two testable hypotheses.

H1: Total savings in a country increase with the number of MFIs (a) active in a country and (b) active over time in the country.

H2: The higher the savings product saturation of a country is, the stronger (a) economic and (b) social developments are.

8 The number of MFIs active in a country is limited proxy for financial sophistication, as naturally the situation is more complex. On the one hand, different MFIs offer different financial services with various outreach due to, for example, regulations or lack of infrastructure. On the other hand, institutions like traditional banks, NGOs, or financial cooperatives could be active in the market as well. 
Hypothesis $\mathrm{H} 1$ tests for the savings saturation of a market. Incremental savings are expected to slow down with the number of active MFIs, meaning that the average total deposits held by an MFI is slowly but linearly decreasing with an increasing number of MFIs active in a country. This means that while overall savings are expected to increase with the number of MFIs, incremental savings per added MFI are expected to diminish with an increase in market saturation. H1 tests for the general increase in savings, but also for this diminished speed of increase depicting savings market saturation ${ }^{9}$. Under H1a all cross-section data as listed countries on the Microfinance Information eXchange (MIX) database ${ }^{10}$ are considered for one year (2008). In the same way an overall increase of savings, but with a linear marginal decrease of average MFI deposits, is expected for the different years of the countries under $\mathrm{H} 1 \mathrm{~b}$. The longitudinal data for $\mathrm{H} 1 \mathrm{~b}$ as well as $\mathrm{H} 2 \mathrm{a} / \mathrm{b}$ will be tested for the annual data of selected countries for differently expected saving product saturation levels. Data from the following four countries serve as a sample case:

1. UK for a developed country with a fully saturated market

2. Bangladesh for a developing country with a fairly saturated market

3. India for an intermediate country with a low saturated market

4. Togo for a low penetration country with a marginally or unsaturated market

Total savings and number of MFI are taken from MIX for the saturation levels of the different countries. Here deposits with standard banks in the UK serve as a benchmark for the highest level of development (neglecting possible differences between developed countries). For the other countries,

9 New MFIs are expected to have less deposits and their growth in deposits depends on the current saturation level of the market. An example of a quick growth due to limited saturation levels is provided by BRI, the only active MFI in Indonesia and therefore being able to attract a huge number of customers over a relatively short period of time.

10 Although data from MIX suffers from a self-selection problem, as MFIs volunteer to provide and decide themselves which information they give, it is the largest database on microfinance freely available for researchers. With this limitation, it still captures differently sized MFIs. MIX considers that MFIs with less than 10,000 borrowers are small, 10,000 to 30,000 borrowers are medium and more than 30,000 are large. The median MFI reporting in the year 2011 is small by this definition. Furthermore, only about $10 \%$ of the MFIs report more than 100,000 clients, although the number of borrowers in the 90th percentile of MFI size keeps increasing every year (from 41,900 borrowers in 2003 to 116,600 borrowers in 2011). When considering the reported depositors, we find that just a few less MFIs report savings to MIX, but at least a quarter indicate that they have no microsavings. As a result, the median MFI reports only 562 depositors in 2011. But similarly to the large MFIs on reported borrowers, MFIs in the 90th percentile have on average 100,000 depositors. 
under $\mathrm{H} 2 \mathrm{a}$ the gross domestic product (per capita) and employment (to population ratio) serve as indicators for economic development. Literacy, gross enrollment, life expectancy, and child mortality serve as educational, health, and general demographic indicators for describing differences in social development under $\mathrm{H} 2 \mathrm{~b}$. All these different development measures are expected to increase with savings saturation, although decreasing in speed with growing incomes. Saturation can only be approximated with this approach by the number of MFIs offering saving products in the respective country.

\section{RESULTS}

For 2008 a total of 698 MFIs from 88 different countries report their accumulated deposits on the MIX database. The number of reporting institutions does not necessarily increase for a country each year. For the three selected countries India, Bangladesh, and Togo together the number of reporting MFIs is shown in Figure 2 for the years 1999-2008, separate for those institutions with and those without deposits. Although the total number of reporting institutions decreases for these countries in the last five years, the proportion of deposit offering MFIs grows substantially. The reason for selecting only a small sample of countries is to have a comparable data set. Once the number of countries is increased, the overlaps between available data (and indicators) between the different countries becomes surprisingly small. This, mainly due to the data limitations in developing countries, would make any more integrative approach fail. Therefore, the provided analysis is for illustration purposes only. Moreover, it is di cult to compare countries which differ on many dimensions. Some of these limitations are overcome in using a simplifying case method where we study a small number of strongly dissimilar countries to bring out general features.

The overall increase in the number on MFIs reporting at MIX is mainly owing to the growing number of MFIs from additional countries than the four investigated in more detail. When examining all data from MIX for the year 2011 , the average number of borrowers is 76,000 and of depositors is 65,000 . However, there seems to be a strong difference between MFIs, with all 1,238 MFIs reporting borrowers, but only 642 MFIs reporting depositors. When removing the MFIs not offering saving products (reporting no depositors), the remaining have on average 121,000 depositors. These MFIs have a slightly lower average number of borrowers $(65,000)$. Thus, MFIs which offer both deposits and borrowings have more depositors than borrowers, which illustrates that microsavings can be important for the poor. Interestingly, those MFIs on 
MIX which do not report depositors are larger institutions, with on average 87,000 borrowers. This is at least partly due to the fact that in many countries, such as India, non-bank MFis were not allowed to take deposits' ${ }^{11}$.

Figure 2: Number of MFIs from India, Bangladesh, and Togo reporting on MIX

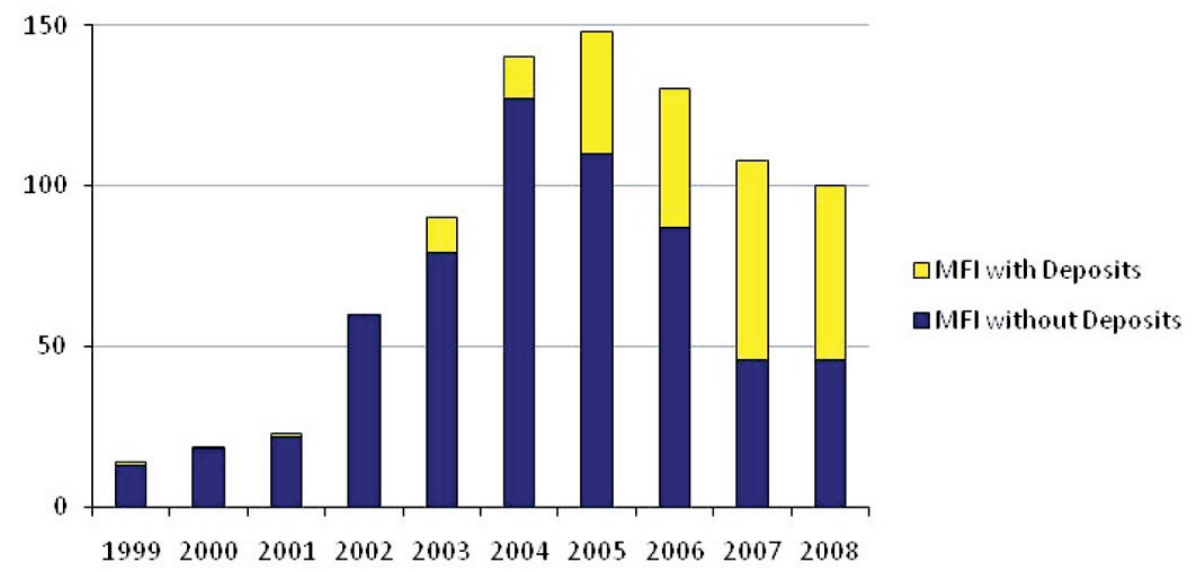

When testing all countries for market saturation, first only those MFIs with deposits are selected and the average deposit per MFI is calculated for these countries. The 2008 MIX country level data supports the assumption under H1a that the savings increase with the number of active MFI in a country. But with an increased number of MFIs active in a country the average deposit per MFI diminishes (Figure 3).

Thus, the postulated negative correlation between number of active MFIs in a country and average deposits per MFI holds when all 88 countries are considered, but this correlation $(\mathrm{r}=-0.15)$ is only marginally significant only $(p=.18)^{12}$. Second, when testing for the changes over time in the different se-

11 The overall correlation between the number of depositors and the number of borrowers is 0.47. However, if those MFIs without depositors are removed, the correlation increases to 0.69. Although no causation can be implied, it becomes clear that MFIs with more depositors provide loans to a higher number of customers.

12 The United Kingdom with 367 scheduled financial institutions and an average of 9 billion US dollars ( 5.8 billion British pounds) per institution in June 2010 by far exceeds our saturation postulation and might only compare within developed countries. After correcting for the country's GDP per capita (PPP), the negative relation still holds for the investigated developing countries ( $\mathrm{r}=-0.09 ; \mathrm{p}=.39$ ), although significant amounts might be differently deposited in standard financial institutions and are not captured under MFI data. 
lected countries under H1b, the longitudinal MIX data for the selected countries does not support the assumption. Figure 4 shows the number of active MFIs in India, Bangladesh, and Togo over the last ten years. These numbers strongly differ between the countries, they do not increase steadily, and deposits are mainly only reported for 2005 to 2008.

Figure 3: Average deposits per MFI separate for countries

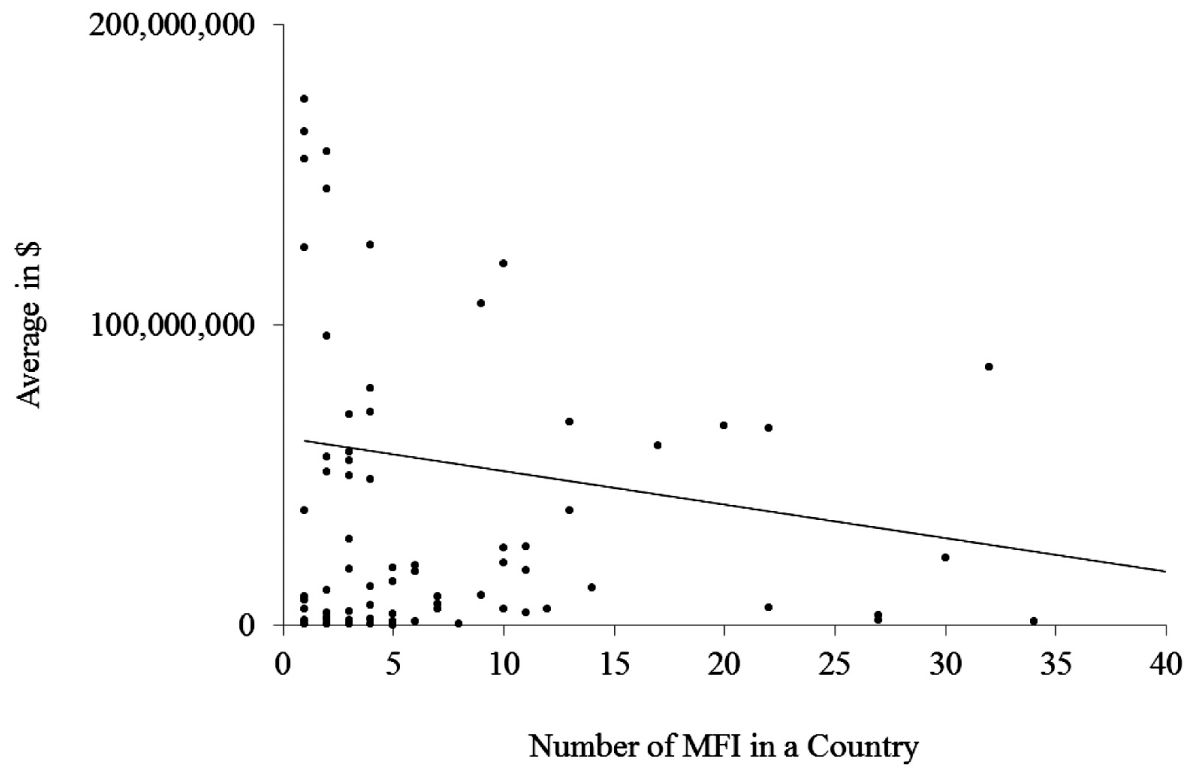

Though when simply plotting the number of active MFI and average deposits, independent of the year they occur, we see (as shown in Figure 5) that the postulated relation holds. The correlation of the yearly averages for the three countries together is negative $(r=-0.11)$, but small and not significant $(\mathrm{p}=.67)$.

This negative relationship does not hold when investigating the three countries separately as illustrated in Figure 6. In Togo the growth is rather limited with a maximum of seven institutions being active in the market. The increase in average deposits is valid due to the first three years with only one institution holding relatively small deposits. The low average deposits in India might be explained by the fact that here MFIs occupy a specific market niche. In general the three countries show rather distinct results for the deposit market of MFIs in these years. 
Figure 4: Number of active MFIs in the different selected countries separated by MFIs with (in light color) and without (in dark color) deposits

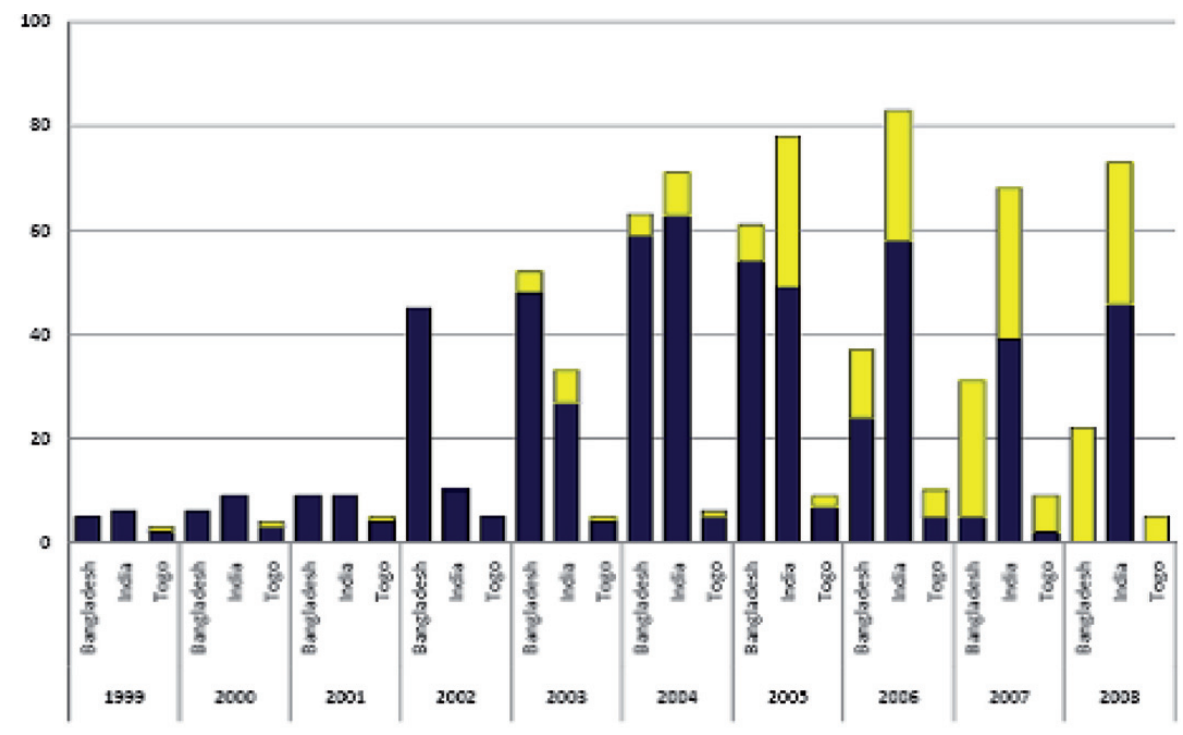

Summing-up, differently postulated market saturation can be assumed, but country specifics complicate the measure of market saturation under H1. The observed markets are different in regard to the structure of financial services, capital migration, and population - to name just a few factors.

Data for evaluating the second hypothesis of an assumed relationship between market saturation and economic as well as social development were taken from the freely available UN (http://data.un.org) and World Bank (http://data.worldbank.org) databases. For the four countries (UK, India, Bangladesh, Togo) the economic measures (GDP, employment rate) and the social measures (literacy, gross enrollment, life expectancy, infant mortality) are shown in Table 1 for the latest year/period available.

The postulated order holds for the corrected (PPP) gross domestic product per capita of the different countries - with Togo being lowest and the UK being highest. The assumption of a higher employment rate for more saturated markets is not supported, with Bangladesh showing the highest employment rate. Regarding the measures of social development, the predicted order is only contradicted for life expectancy and infant mortality where India and Bangladesh change positions. Thus, out of a total of 24 social devel- 
Figure 5: Average yearly deposits for MFIs of selected countries in the years 1999 to 2008

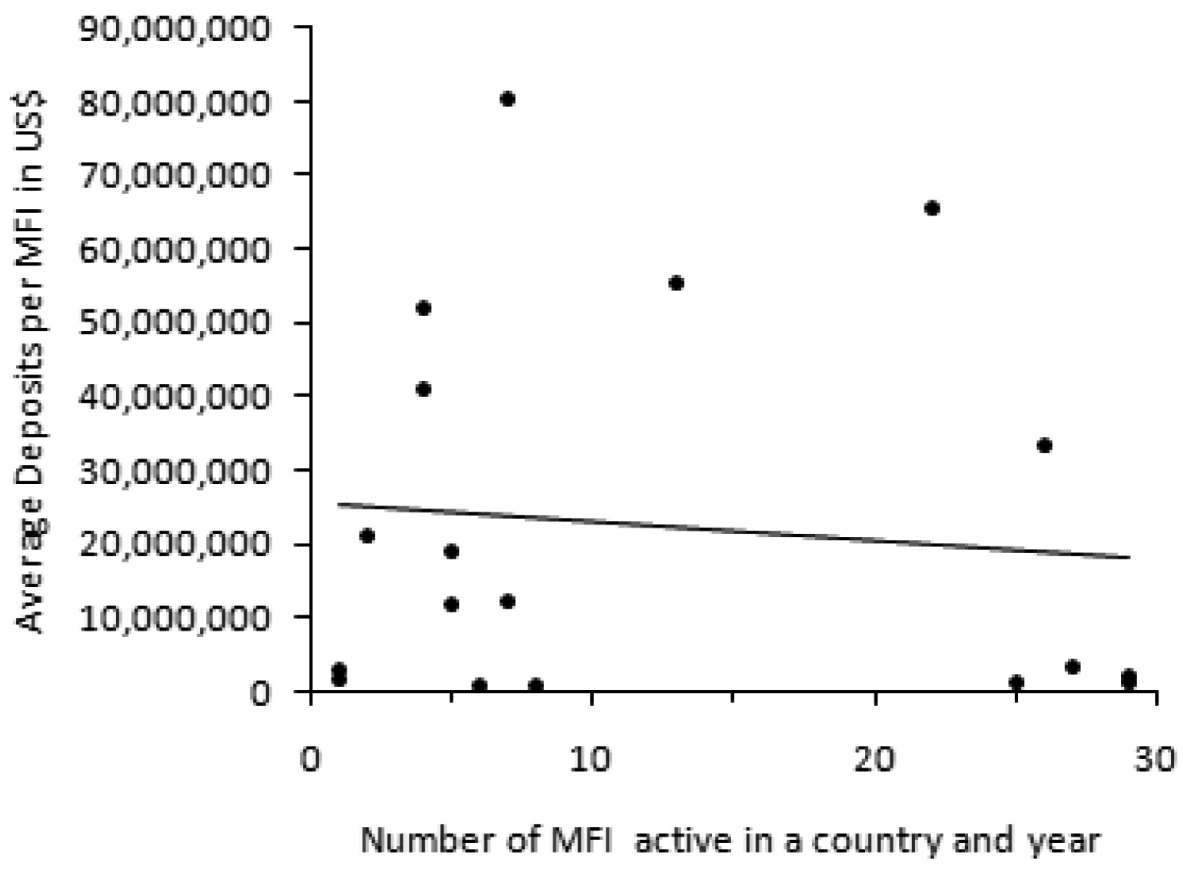

opment comparisons between the individual countries only two are not confirmed. The combined Human Development Index (published by the United Nations for 2007) also reflects the proposed relation between the four countries with values of 49.9, 54.3, 61.2, and 94.7 respectively for Togo, Bangladesh, India, and the UK. The correlation between GDP (per capita PPP as an approximation for market saturation) and the different social development measures further supports this relation with literacy $(\mathrm{r}=0.97$; $\mathrm{p}=.04)$, enrollment $(\mathrm{r}=0.90 ; \mathrm{p}=.10)$, life expectancy $(\mathrm{r}=0.98 ; \mathrm{p}=.02)$, and infant mortality $(r=-0.93 ; p=.07)$ all showing strong dependencies for our sample of four countries. The economic measures do not show significant inter-correlations though, as only market saturation and GDP are positively correlated $(\mathrm{r}=0.87 ; \mathrm{p}=.13)$, although with market saturation not being in the assumed direction of decreasing average deposits with an increasing numbers of financial institutions. For a broader analysis a more stringent measure for market saturation with regard to market size, population density, and type of institution is needed. 
Figure 6: Average deposits for MFIs separate for the selected countries

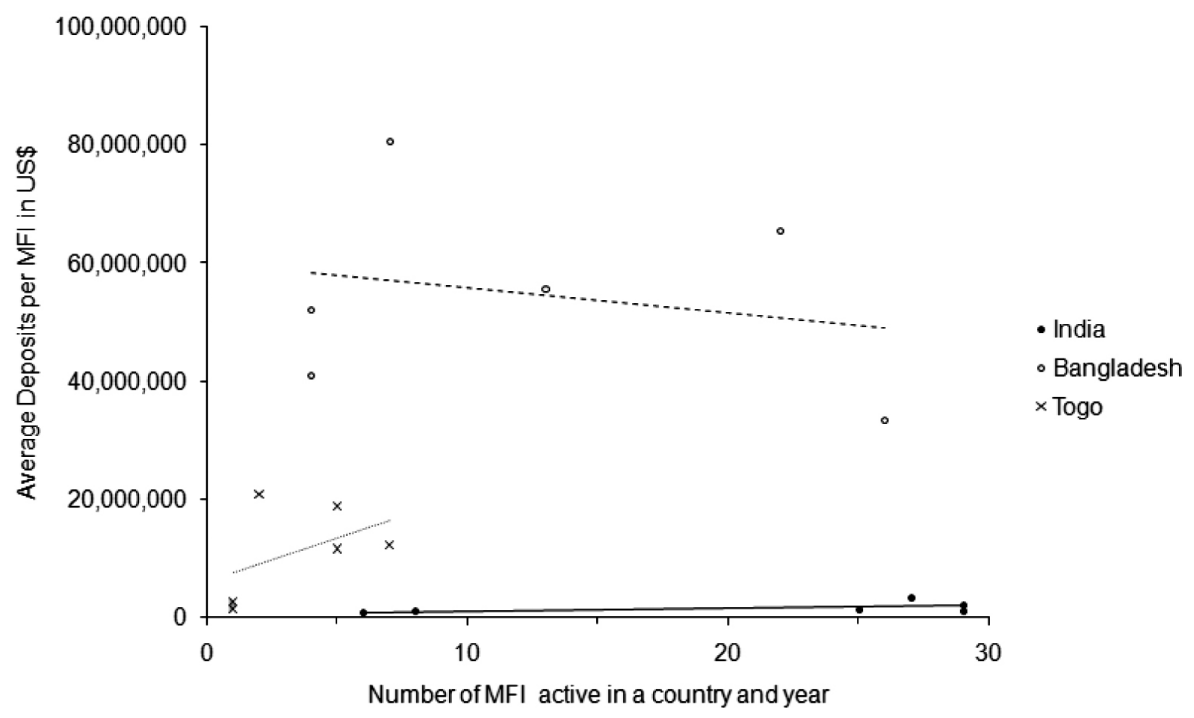

Table 1: Measure of development for differently saturated countries with the corresponding year in brackets

\begin{tabular}{|l|c|c|c|c|}
\hline Development & Togo & Bangladesh & India & UK \\
\hline Saturation in million US\$a & 18.9 & 65.5 & 4,914 & 8,950 \\
\hline GDP per capita (2008) PPP in US\$ & 830 & 1,335 & 2,946 & 35,468 \\
\hline $\begin{array}{l}\text { Employment to population ratio } \\
\text { (2008) ages 15-24 in \% }\end{array}$ & 52.7 & 56.0 & 39.6 & 55.8 \\
\hline Literacy (2003-2008) of aged 15+ in \% & 53 & 54 & 66 & 99 \\
\hline $\begin{array}{l}\text { Net gross enrollment (2009) } \\
\text { to primary education in \% }\end{array}$ & 80.1 & 86.5 & 88.7 & 98.4 \\
\hline $\begin{array}{l}\text { Life expectancy at birth } \\
(2005-2010) \text { in years }\end{array}$ & 71.4 & 44.7 & 54.6 & 4.81 \\
\hline $\begin{array}{l}\text { Infant mortality per births } \\
\text { (2005-2010) in \% }\end{array}$ & 62.4 & 63.9 & 79.4 \\
\hline
\end{tabular}

a Average deposits per MFI (2008) in the cases of Togo / Bangladesh and per scheduled commercial bank (2009) for India / United Kingdom.

$\mathrm{b}$ The combined expectancy for both sexes for the span of five years. 


\section{DISCUSSION}

Together our results clearly show that Keynes's paradox of thrift (also discussed under the term "fallacy of savings") is a false assumption, and instead that more savings keeps our society growing. The better saturated a savings market is, the more deposits there are and the stronger the economic as well as social development. Thus, we argue against too much externally provided liquidity and instead to focus on building savings internally - by addressing demands for self-control (with corresponding individual/regional differences) which supports time consistent behavior via saving to enable sustainable development.

Thrift can clearly be interpreted as a rather temporal danger, with in contrast savings fulfilling a long term condition for growth. A person saves to allow for future freedom of choice and to advantage himself over others. This self-interest guided behavior can ultimately, through non-consumption, lead to benefits for others by providing trade, labor, etc. Generally, self-interest guided saving is needed first for achieving sustainable development later. Although individual riches do not always increase general wealth, according to our observations and supported by the investigated data, a minimum saving rate is a basic requirement for development. With a strong increase in savings for a small number of MFIs (as in Togo for the last years) this minimum requirement of providing means for saving can easily be met. The slowdown in marginal increase per MFI clearly indicates a possible maximum for saving levels. The theorem of a "golden saving rate" similarly argues for an optimal amount of available capital, linked here to the units of labor and corresponding consumption levels. However, defining exact and optimal savings levels (with a strong increase in the beginning, a slowdown up to a plateau, and a decline later) appears to be di cult and not only in developing countries. Furthermore, savings need not linearly relate to labor as labor might increase substantially with only limited but su cient savings. Here a clear definition of savings behavior is needed (i.e., Ahiakpor, 1995). In Keynes's definition, with the hording of cash, negative effects and the fallacy of composition can result. However, most savings behavior can be defined as the purchase of interest-or profit-earning assets, which directly leads to consumption elsewhere and possibly positive long-term effects. In this regard, we stress the importance of savings saturation by the development of financial services which reflect the regional and individual demands for selfcontrol. The limited accessibility to financial services in developing countries has been stressed and changes have been demanded repeatedly (an overview is provided by Claessens, 2006). External investments could help 
here with building up the financial infrastructure, but the desire for worldwide accessibility to financial services might need new ways besides infrastructural improvements. Here new technologies such as mobile or branchless banking provide further possibilities (i.e., Ashta, 2011; Mas, 2009). Before elaborating on financial dependencies of lending and interest rates, a functioning financial services structure needs to be provided all over the world if not as a global structure of high street banks, then over the Internet or the phone where transaction costs are substantially lower.

In any case, to evaluate the relationship between savings rates and a country's development, longer time spans are needed. The individual increase in savings always comes with the danger that accumulated wealth, which has required the labor and pain of years, could be destroyed in a few moments of imprudence. In Togo, for example, MFIs are now allowed to incorporate savings products in their offer, often making deposits compulsory for later loans or simply using it as collateral. But the increase in deposits is a rather recent activity and substantial effects on economic and social development can only be expected over longer time horizons, with the self-control issue being sustained.

\subsection{Shortcomings and recommendations}

The proposed measure of saving saturation (as average total deposits per MFI) holds a couple of shortcomings and further investigations of savings behavior in developing countries could directly focus regional and individual components of saving. The paradox of thrift can simply be reformulated as a question of spending redistribution as a little for all can change a lot in social terms. A reduction of inequality can be achieved by savings of the poor where relatively small improvements for a large number would mean a huge achievement. Thus, it is important to differentiate between forms of deposits. The amount per individual could be more important for poverty alleviation than the absolute saving or the ratio between investments and savings. Important for individual savings is the number of depositors or average deposits per person. These measures and how they relate to a country's development could be easily investigated in more detail. The current investigation also does not account for market consolidation. The number of total MFIs active in a country over time might slow down or even decrease by the merging of different companies, but which would together still offer a larger number of savings products. Therefore the market saturation of savings products might change without necessarily being reflected in the number of active financial services providers. A stronger diversification in savings 
products in developed countries might increase average deposits per bank. Moreover, the distinction between different institutions with different purposes and aims has to be accounted for ${ }^{13}$.

These issues complicate the estimation of asymptotic market saturation. The amount of savings products is positively related to the number of MFIs offering deposits in a country, but nevertheless exact numbers are di cult to obtain. The general measure of savings per MFI only provides an approximation of market saturation. Close to full saturation additional increments are assumed to be limited. A better saturation indicator could make the intermediate link to development obsolete as it can directly serve as a measure for financial development. Defining saving market saturation by the marginal increase in deposits for an additional MFI (with a specific threshold) has its practical limitations. A useful heuristic for determining the level of market saturation could be the observation of a decrease in average savings per MFI, which would be the first indicator of reaching saturation on a relatively low level. Until this decrease is observed, implementing further savings products offerings should be pursued. The upper limit of savings saturation could be reached by a consecutive and substantial (approximately 10\%) decrease of the average deposits per MFI. This definition is a purely hypothetical estimate which remains to be tested and refined. It also might remain more flexible as for more saturated markets in developed countries further increases of individual savings levels could be achieved by offering sophisticated self-control tools for saving behavior.

\subsection{Managerial and business applications}

In this paper we deliberately do not distinguish between saving inclination in developing and developed countries. It is assumed that in both selfcontrol tools are needed, only that in more developed countries these tools are already widely available. Observations of self-control which were made in developed countries can be directly transferred to developing countries, possibly with a much stronger urge for smoothing behavior over time. Thus, lack of selfcontrol for savings behavior can be postulated in the same way

13 To evaluate different financial institutions, Bauchet and Morduch (2013) compare microfinance with small and medium enterprises in the BRICS (Brasil, Russia, India,China, and South Africa) countries. This connects financial institutions in developing with institutions in developed countries. Their results stress differences in demands which are served by one or the other institution. New initiatives like the BRICS bank can been seen under a similar aim of showing new ways for improving financial services for the masses and improving diversity in the financial sector. 
for people in developing countries as well - possibly with a stronger negative effect than in developed countries. One important reason for obvious differences between developed and developing countries could be the development of the financial services market which provides, in the former, a means for self-control and is, in the latter, often self-organized with only informal solutions. Differences can also be attributed to the various structures of the banking system which can partly be explained by local circumstances.

The banking systems, or lack thereof, make significant differences owing to local conditions. As a result, in less saturated markets there is less competition between suppliers to develop and offer savings products to attract different people. Many people living in unsaturated savings markets, like the larger African regions, have no or only little means for self-control. In partially saturated markets, like the major Asian regions, the demand for savings is only satisfied in some parts and more savings offers are needed. In both regions there is a huge scope for improvement with MFIs/banks diversifying their products. Under the current conditions of little or no market competition, changes are not expected to occur automatically and further structural supporting initiatives are needed. Markets which are becoming more saturated and offering more savings products, also by adopting products from the older European markets, can show substantial developmental leaps (i.e., Bangladesh, Bosnia, Bolivia), although it is di cult to determine post hoc which development came first, and global long term studies are needed of differently saturated savings markets.

\section{CONCLUSION AND FUTURE RESEARCH DIRECTION}

We propose savings market saturation (with its limitations) as a measure for microfinance initiatives with a clear relation to economic as well as social development. The main aim of poverty reduction is redefined as the tackling of behavioral weaknesses and the fostering of self-discipline. Irrespective of a MFI's strategy, a larger variety of savings products and a corresponding improvement in market saturation of financial products is expected to support this aim. But naturally the development of a country depends on its financial growth as the financial system and general institutions could play an important role for sustained development. In our understanding, the financial system should be oriented on the improvement of individual savings over the long term leading to a cognitively grounded approach to finance (also compare Otto, 2010). This could also play an important part in protecting institutions themselves from financial shocks. Marconi and Mosley 
(2006) provide an example for the relation of institutions offering savings and a reduction in the economic crisis in Bolivia. Hollis and Sweetman (2007) stress, in a 19th century Irish loan fund example, the potential of depositors controlling the expenses of microfinance organizations. Sustainability appears to be the key factor for development on the individual as well as the institutional level. In line with Paxton and Fruman (1997), we argue for more diversity in savings products to succeed in both the outreach and sustainability dimensions. Diversity further supports the search for adaptive solutions, which are superior to planning objectives as William Easterly (2006) nicely points out in his contribution. Similarly diversity in savings could be adapted to various demands in self-control. Different product characteristics have been proposed to successfully guide self-control. In the microfinance literature peer pressure and monitoring or regular repayments and fixed installments have been proposed to describe successful loan products. Similarly for saving products, to enforce saving behaviors, individually adapted tools for self-control strategies have to be provided. This means including mechanisms which can be chosen voluntarily to improve future behavior in line with individual demands. Only su cient product differences and intelligent product design can meet this diversity in self-control including areas of decision space restrictions, supporting cues by the environment, and behavior consistent contingency structures. Independent of the realization of a specific product offer, only diversity appears to provide the necessary potential for sustainable development.

\section{References}

Adams D.W., 1978, "Mobilizing household savings through rural financial markets", Economic Development and Cultural Change, Vol. 26(3), pp. 547-560.

Adams D.W., 1984, "Do rural financial savings matter", Studies in Rural Finance, Economics and Sociology Occasional Paper No. 1083, Columbus: Ohio State University.

Adams D.W., 1988, "The conundrum of successful credit Projects in floundering rural financial markets", Economic Development and Cultural Change, Vol. 36(2), pp. 355367.

Ahiakpor J.C.W., 1995, “A paradox of thrift or Keynes's misrepresentation of savings in the classical theory of growth", Southern Economic Journal, Vol. 62, pp. 16-33.

Ainslie G., 1975, "Specious reward: a behavioral theory of impulsiveness and impulse control", Psychological Bulletin, Vol. 82(4), pp. 463-496. 
Allaire V., A. Ashta, L. Attuel-Mendes and K. Krishnaswamy, 2009, "The success of Moroccan microfinance institutions: more than just culture?", Euro-Mediterranean Economics and Finance Review, Vol. 4(3, Special Issue for IFC 5), pp. 53-74.

Amin S., A.S. Rai and G. Topa, 2003, “Does microcredit reach the poor and vulnerable? Evidence from northern Bangladesh", Journal of Development Economics, Vol. 70(1), pp. 59-82.

Armendàriz B. and J. Morduch, 2010, "The economics of microfinance” (Chapter 10), Cambridge, MA: MIT Press.

Ashta A., 2011, "Advanced technologies for microfinance", Hershey, PA: IGI Global.

Ashta A., 2009, "Micro-credit capital flows and interest rates: an alternative explanation", Journal of Economic Issues, Vol. 43(3), pp. 661-684.

Ashta A. and N.S. Fall, 2009, "Institutional analysis to understand the growth of microfinance institutions in West African economic and monetary union", Cahiers du CEREN, Vol. 29, pp. 27-45.

Ashta A., S. Khan and P.E. Otto, 2011, "Does microfinance cause or reduce suicides? Policy recommendations for reducing borrower stress", SSRN Working Paper 1715442.

Barr M., 2005, "Microfinance and financial development", Michigan Journal of International Law, Vol. 26, pp. 271-296.

Bateman M., 2010, “Why microfinance doesn't work? The destructive rise of local neo-liberalism" (Chapter 3), London, United Kingdom: Zed Books.

Bauchet J. and J. Morduch, 2013, "Is micro too small? Microcredit vs. SME finance", World Development, Vol. 43, pp. 288-297.

Bauer M., J. Chytilov'a and J. Morduch, 2012, "Behavioral foundations of microcredit: experimental and survey evidence from rural India", American Economics Review, Vol. 102(2), pp. 1118-1139.

Chen, G., S. Rasmussen and X. Reille, 2010, "Growth and vulnerabilities in microfinance", Focus Note 61. Washington, D.C.: CGAP.

Claessens S., 2006, "Access to financial services: a review of the issues and public policy objectives", The World Bank Research Observer, Vol. 21(2), pp. 207-240.

Collins D., J. Morduch, S. Rutherford and O. Ruthven, 2010, "Portfolios of the poor: how the world's poor live on $\$ 2$ a day", Ranikhet, India: Permanent Black.

Constantinou D. and A. Ashta, 2011, "Financial crisis: lessons from microfinance", Strategic Change: Briefings in Entrepreneurial Finance, Vol. 20(5/6), pp. 187-203.

Dupas P. and J. Robinson, 2008, Saving constraints and the microenterprise development: evidence from a field experiment in Kenya", Working Paper.

Easterly W., 2006, “The white man's burden. Why the West's efforts to aid the rest have done so much ill and so little good", New York: Penguin Press.

Fiebig M., A. Hannig and S. Wisniwski, 1999, "Saving in the context of microfinance: state of knowledge", Eschborn: CGAP Working Group on Savings Mobilization. 
Freud S., 1914/1956, "Formulation on the two principles of mental functioning", In: J. Stachley and A. Freud (Eds.) The Standard Edition of the Complete Psychological Works of Siegmund Freud (Vol. 12), London: Hogarth.

Gadway J.O. and M.G. O'Donnell, 1996, "Financing micro-enterprises and rural smallholders", Inter-American Development Bank Working Paper.

Gugerty M.K., 2007, “You can't save alone: Commitment in rotating savings and credit associations in Kenya", Economic Development and Cultural Change, Vol. 55(2), pp. 251-282.

Hollis A. and A. Sweetman, 2007, "The role of local depositors in controlling expenses in small-scale financial intermediation: An empirical analysis", Economica, Vol. 74(296), pp. 713-735.

Hulme D., 2000, "Impact assessment methodologies for microfinance: theory, experience and better practice", World Development, Vol. 28(1), pp. 79-98.

Keynes J.M., 1936, "The general theory of employment, interest and money" (Vol. 7), New York: Macmillan.

Laibson D.I., 1996, "Hyperbolic discount functions, undersaving, and saving policy", NBER Working Paper 5635.

Marconi R. and P. Mosley, 2006, "Bolivia during the global crisis 1998-2004: Towards a macroeconomics of microfinance", Journal of International Development, Vol. 18, pp. 237-261.

Mas I., 2009, "Economics of branchless banking", Innovations, Vol. 4(2), pp. 57-75.

Matin I., D. Hulme and S. Rutherford, 2002, "Finance for the poor: from microcredit to microfinancial services", Journal of International Development, Vol. 14(2), pp. 273294.

Morduch J., 1999, "The microfinance promise", Journal of Economic Literature, Vol. 37(4), 1569-1614.

Mosley P. and D. Hulme, 1998, "Microenterprise finance: is there a conflict between growth and poverty alleviation?",Word Development, Vol. 26(5), pp. 783-790.

Nash R.T. and W.P. Gram, 1969, "A neglected early statement of the paradox of thrift", History of Political Economy, Vol. 1(2), pp. 392-400.

Otero M., 1989, "A handful of rice: Savings mobilization by micro-enterprise programs and perspectives for the future", Monograph Series 3, Washington DC.

Otto P.E., 2010, “Cognitive finance: behavioral strategies of spending, saving, and investing", Hauppauge, NY: Nova Science Publishers.

Otto P.E., G.B. Davies and N. Chater, 2007, “Note on ways of saving: mental mechanisms as tools for self-control?", Global Business and Economics Review, Vol. 9(2-3), pp. 227-254.

Patten R.H., J.K. Rosengard and Jr.D.E. Johnston, 2001, “Microfinance success amidst macroeconomic failure: the experience of Bank Rakyat Indonesia during the East Asian crisis", World Development, Vol. 29(6), pp.10571069. 
Paxton J. and C. Fruman, 1997, “Outreach and sustainability: a comparative analysis of saving-first vs. credit-first financial institutions", World Bank Working Paper 24932.

Price B., 2010, "Chapters on practical political economy: being the substance of lectures delivered in the University of Oxford", Oxford: Nabu Press (reproduction of the original publication in the year 1878 by Paul \& Co).

Rhyne E., 2001, "Commercialization and crisis in Bolivian microfinance", Bethesda, MD: Microenterprise Best Practices.

Sachs J.D., 2005, “The end of poverty: economic possibilities for our time”, New York, NY: Penguin Books.

Schelling T.C., 1980, “The strategy of conflict", Cambridge, MA: Harvard University Press.

Schelling T.C., 1984, "Self-command in practice, in policy, and in a theory of rational choice", American Economic Review, Vol. 74(2), pp. 1-11.

Smets P., 2005, "Changing financial mutuals in urban India: practice, functions, trust and development trajectories" (pp.151-182), In: Mutualist microfinance: informal savings funds from the global periphery to the core? Abram de Swaan and Marcel van der Linden (Eds.), Amsterdam, Netherlands: Aksant Academic Publishers.

Sunstein C.R. and R.H. Thaler, 2003, "Libertarian paternalism is not an oxymoron", University of Chicago Law Review, Vol. 70(4), pp. 1159-1199.

Swaan A.d., 2005, "Mutual funds: then and here, now and there: informal savings and insurance funds in the nineteenth-century West and the present non-western world" (pp.11-30), In: Mutualist microfinance: informal savings funds from the global periphery to the core? Abram de Swaan and Marcel van der Linden (Eds.), Amsterdam, Netherlands: Aksant Academic Publishers.

Swaan A.d. and M.v.d. Linden, 2005, "Mutualist microfinance: informal savings funds from the global periphery to the core?", Amsterdam, Netherlands: Aksant Academic Publishers.

Tavanti M., 2013, “Before microfinance: the social value of microsavings in Vincentian poverty reduction", Journal of Business Ethics, Vol. 112, pp. 697-706.

Thaler R.H., 1985, "Mental accounting and consumer choice", Marketing Science, Vol. 4(3), pp. 199-214.

Thaler R.H. and H.M. Shefrin, 1981, "An economic theory of self-control", Journal of Political Economy, Vol. 89(2), pp. 392-406.

Thaler R.H., C.R. Sunstein and J.P. Balz, 2010, "Choice architecture”, SSRN Working Paper 1583509.

Vogel R.C. and P. Burkett, 1986, “Deposit mobilization in developing countries: The importance of reciprocity in lending", Journal of Developing Areas, Vol. 20, pp. 425-438.

Vogelgesang U., 2003, "Microfinance in times of crisis: the effects of competition, rising indebtedness, and economic crisis on repayment behavior", World Development, Vol. 31(12), pp. 2085-2114. 
Wagle U.R., 2010, “Does low inequality cause low poverty? Evidence from high-income and developing countries", Poverty E Public Policy, Vol. 2(3), pp. 29-52.

Weiss J. and H. Montgomery, 2005, “Great expectation: microfinance and poverty reduction in Asia and Latin America", Oxford Development Studies, Vol. 33(3-4), pp. 391-416.

Yunus M., 2003, "Banker to the poor: micro-lending and the battle against world poverty", New York: Public Affairs.

\section{Acknowledgments}

We would like to thank Glòria Estapé-Dubreuil and other participants of the ITEM2 conference as well as participants from the CEREN-CERMi meeting at ESC Dijon for their useful comments and feedback regarding an earlier version of this paper.

\section{Résumé}

Le comportement lié à l'épargne pourrait conditionner le développement économique de plusieurs façons possibles. Le paradoxe de l'épargne souligne les effets négatifs de l'augmentation de l'épargne individuelle. Comment cette relation se transpose-t-elle à la micro-finance et à la micro-épargne en particulier? Sur la base des données économiques de pays à niveau de développement différent, nous étudions la relation décrite par le triangle représenté par la disponibilité des produits d'épargne, le comportement d'épargne et le développement économique. Les données confortent l'hypothèse du triangle de saturation proposée ici. On observe qu'avec une augmentation de nombre d'IMFs actives dans un pays, le dépôt moyen par MFI diminue. En outre, la saturation des produits d'épargne d'un pays est autant liée au développement économique que social de ce pays. 
